Article

\title{
Correlation between Zn-Rich Phase and Corrosion/Oxidation Behavior of Sn-8Zn-3Bi Alloy
}

\author{
Xin Zhang ${ }^{1}$, Chong $\mathrm{Li}^{1, *}$, Zhiming Gao ${ }^{1}$, Yongchang Liu ${ }^{1}$, Zongqing Ma ${ }^{1}$, Liming $\mathrm{Yu}^{1}$ and \\ Huijun $\mathrm{Li}^{2}$ \\ 1 Tianjin Key Lab of Composite and Functional Materials, School of Materials Science and Engineering, \\ Tianjin University, Tianjin 300350, China; zhang.xin.dream@163.com (X.Z.); gaozhiming@tju.edu.cn (Z.G.); \\ licmtju@163.com (Y.L.); mzq0320@163.com (Z.M.); lmyu@tju.edu.cn (L.Y.) \\ 2 School of Mechanical, Materials and Mechatronic Engineering, University of Wollongong, Wollongong, \\ New South Wales 2522, Australia; huijun@uow.edu.au \\ * Correspondence: lichongme@tju.edu.cn; Tel.: +86-130-2139-8676
}

Academic Editor: Soran Birosca

Received: 13 June 2016; Accepted: 20 July 2016; Published: 25 July 2016

\begin{abstract}
The microstructure of Sn-8Zn-3Bi alloy was refined by increasing the solidification rate and the correlation between Zn-rich phase and the corrosion/oxidation behavior of the alloy was investigated. The $\mathrm{Zn}$-rich phase transforms from coarse flakes to fine needles dispersed in the $\beta$-Sn matrix with the increase of the cooling rate. The transformation of $\mathrm{Zn}$-rich precipitates enhances the anticorrosive ability of $\mathrm{Sn}-8 \mathrm{Zn}-3 \mathrm{Bi}$ alloy in $3.5 \mathrm{wt}$ \% $\mathrm{NaCl}$ solution. On the contrary, $\mathrm{Sn}-8 \mathrm{Zn}-3 \mathrm{Bi}$ alloy with a fine needle-like $\mathrm{Zn}$-rich phase shows poor oxidation resistance under air atmosphere, due to the fast diffusion of $\mathrm{Zn}$ atoms in $\mathrm{Sn}$ matrix.
\end{abstract}

Keywords: Sn-Zn-Bi alloys; microstructure; Zn-rich phase; corrosion; oxidation

\section{Introduction}

$\mathrm{Sn}-\mathrm{Pb}$ alloys have long been extensively used in microelectronic packaging industries due to their good wettability, excellent physical properties, low cost and low melting point [1]. However, in recent years, solder materials design has shifted focus to lead-free solder due to lead toxicity and its harmful effects on human health and the environment [2]. Accordingly, many lead-free Sn-based alloys with the addition of alloying elements have been investigated, such as $\mathrm{Zn}, \mathrm{Ag}, \mathrm{Cu}, \mathrm{Bi}, \mathrm{In}, \mathrm{Ni}$. Also, their microstructures, mechanical properties and solderability have been reported [3-10].

Among these lead-free solder alloys, the $\mathrm{Sn}-\mathrm{Zn}$ based solder alloy has been found to be a promising candidate to replace the existing $\mathrm{Sn}-\mathrm{Pb}$ eutectic solder, due to its relatively low melting temperature, superior mechanical properties at room temperature and relatively low cost [11-15]. Moreover, $\mathrm{Bi}$ is a surface active element and can reduce surface tension and eutectic temperature of the $\mathrm{Sn}-\mathrm{Zn}$ system. So it has been added to the $\mathrm{Sn}-\mathrm{Zn}$ alloy to form the ternary eutectic $\mathrm{Sn}-8 \mathrm{Zn}-3 \mathrm{Bi}$ with improved wettability and lower melting point [16,17].

To achieve high reliability in the long-term use process, solder materials are also required to exhibit high resistance to corrosion and oxidation conditions such as moisture, air pollutants and oceanic environments. In addition, relatively limited studies addressing their corrosion and oxidation behaviors are available [18-21]. So in the present work, the microstructure of Sn-8Zn-3Bi was manipulated by changing the solidification rate. We also concentrated on the relationship between the $\mathrm{Zn}$-rich phase and the corrosion/oxidation behavior of the $\mathrm{Sn}-8 \mathrm{Zn}-3 \mathrm{Bi}$ alloy. These results provide crucial experimental input as a guide for fabricating $\mathrm{Sn}-\mathrm{Zn}-\mathrm{Bi}$ alloys in various harsh environments. It may be of reference value for researching the corrosion/oxidation behavior of other lead-free Sn-based alloys. 


\section{Experimental Procedures}

The Sn-8Zn-3Bi alloy was prepared from the commercial pure $\mathrm{Sn}, \mathrm{Zn}$ and $\mathrm{Bi}(\mathrm{Sn}, \mathrm{Zn}$ and Bi ingots with purity of $99.9 \%$ ). Required quantities of the ingot were melted at $450{ }^{\circ} \mathrm{C}$ in a $25 \mathrm{~kW}$ medium frequency induction furnace under an inert argon atmosphere. The molten $\mathrm{Sn}-8 \mathrm{Zn}-3 \mathrm{Bi}$ alloy was homogenized at $500{ }^{\circ} \mathrm{C}$, and then poured in a steel mold and porcelain crucible to prepare the chill cast ingot with rapid cooling rate (about $8{ }^{\circ} \mathrm{C} / \mathrm{S}$ ) and slow cooling rate (about $1{ }^{\circ} \mathrm{C} / \mathrm{S}$ ), respectively. Metallographic specimens were polished by a standard procedure. The microstructure characteristics of the specimens were observed using scanning electron microscope (Hitachi Model No. S4800).

Corrosion test was performed with samples in $3.5 \mathrm{wt} . \% \mathrm{NaCl}$ solution, and its results were evaluated according to weight loss measurement. For the weight loss-measuring test, the samples $(30 \mathrm{~mm} \times 30 \mathrm{~mm} \times 1 \mathrm{~mm}$ ) were immersed in the $\mathrm{NaCl}$ solution for three, five, seven days. All electrochemical measurements were performed at room temperature $\left(25 \pm 2{ }^{\circ} \mathrm{C}\right)$ in a conventional three-electrode cell, a platinum plate as the counter electrode (CE) and a saturated calomel electrode (SCE) as the reference electrode (RE). The polarization curves were recorded in the anodic direction in the range of $-1500 \mathrm{mV}$ to $2000 \mathrm{mV}$ at a scan rate of $0.5 \mathrm{mV} / \mathrm{s}$. The oxidation property of the Sn-8Zn-3Bi solder alloy was conducted by a thermal gravimetric analyzer (TGA). The specimens were heated to $170{ }^{\circ} \mathrm{C}$ at a heating rate of $10^{\circ} \mathrm{C} / \mathrm{min}$ and hold for $2 \mathrm{~h}$ under air atmosphere.

Auger electron spectroscopy (AES) sputtering was used to analyze the distribution of Sn, Zn, $\mathrm{Bi}$ and $\mathrm{O}$ on the solder surface. The sputtering speed was $4 \mathrm{~nm} / \mathrm{m}$. Both the compositions and the chemical valence states of the elements in the corroded alloy were examined by using X-ray photoelectron spectroscopy (XPS) technique. And the calculation of the data was performed using XPS Peak 4.1 peak-fitting software.

\section{Results and Discussion}

Figure 1 shows the microstructures of slow cooling (SC) and rapid cooling (RC) Sn-8Zn-3Bi alloy. As shown in Figure 1a,c, it can be seen that coarse, long, flake-like Zn-rich phase uniformly distributes in the $\beta$-Sn matrix in the SC Sn-8Zn-3Bi alloy. Due to the large solid solubility of Bi in Sn, the addition of $3 \mathrm{wt} . \% \mathrm{Bi}$ forms a solid solution of Bi in the Sn matrix, resulting in the invisibility of Bi in the microstructure. Notably, the rapid cooling rate obviously refines the solidification microstructure of Sn-8Zn-3Bi alloy (Figure 1b,d). The Zn-rich phase transforms to fine, short, needle-like precipitates dispersed in the $\beta$-Sn matrix in the rapid cooling $S n-8 Z n-3 B i$ alloy.

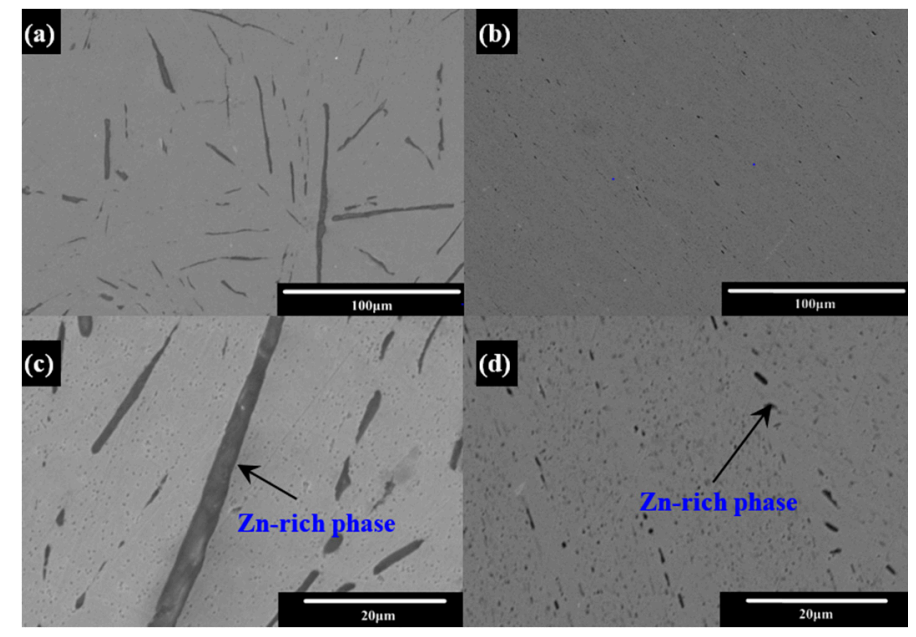

Figure 1. Microstructures of $\mathrm{Sn}-8 \mathrm{Zn}-3 \mathrm{Bi}$ alloy: (a) slow cooling rate (SC); (b) rapid cooling rate (RC); (c) enlarged morphology of Zn-rich phase in (a); (d) enlarged morphology of Zn-rich phase in (b). 
Figure 2 shows the weight loss of the samples as a function of the duration time in $3.5 \mathrm{wt} . \% \mathrm{NaCl}$ solution. For the slow cooling and rapid cooling $\mathrm{Sn}-8 \mathrm{Zn}-3 \mathrm{Bi}$ alloy, the weight loss increased with the duration time. Moreover, it needs to be pointed out that compared to Sn-8Zn-3Bi (SC), the alloy with the rapid cooling rate suffers from comparatively less corrosion attack and shows better corrosion resistance. The open circuit potential (OCP) against time (Eocp-t) curves of both alloys measured in $\mathrm{NaCl} 3.5$ wt.\% solution are shown in Figure 3. As seen from Figure 3, the values of OCP (EOCP) of $\mathrm{Sn}-8 \mathrm{Zn}-3 \mathrm{Bi}$ alloy gradually tend to be constant. From a comparison of curves, a positive shift in the EOCP was clearly found when the cooling rate was increased, which reveals that RC Sn-8Zn-3Bi alloy provides better protection.

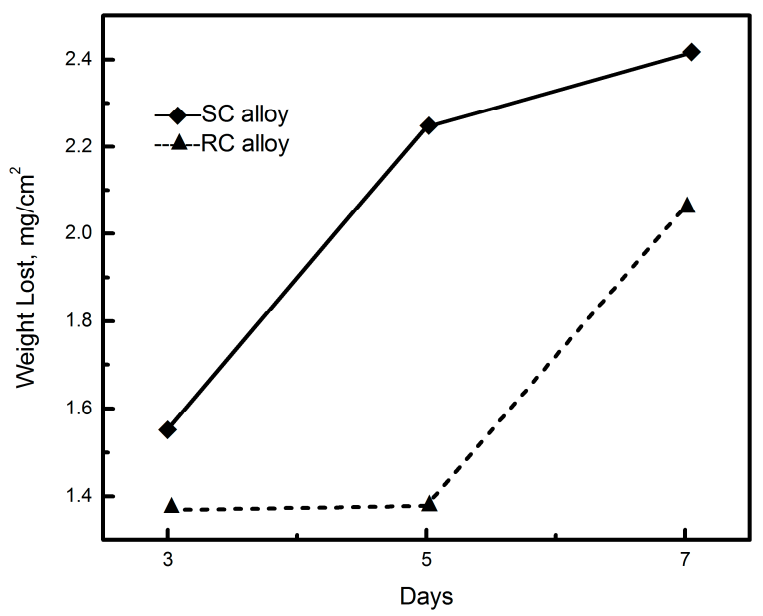

Figure 2. Weight loss of $\mathrm{Sn}-8 \mathrm{Zn}-3 \mathrm{Bi}$ alloy with two solidification rates as a function of duration time in $3.5 \% \mathrm{NaCl}$ environment.

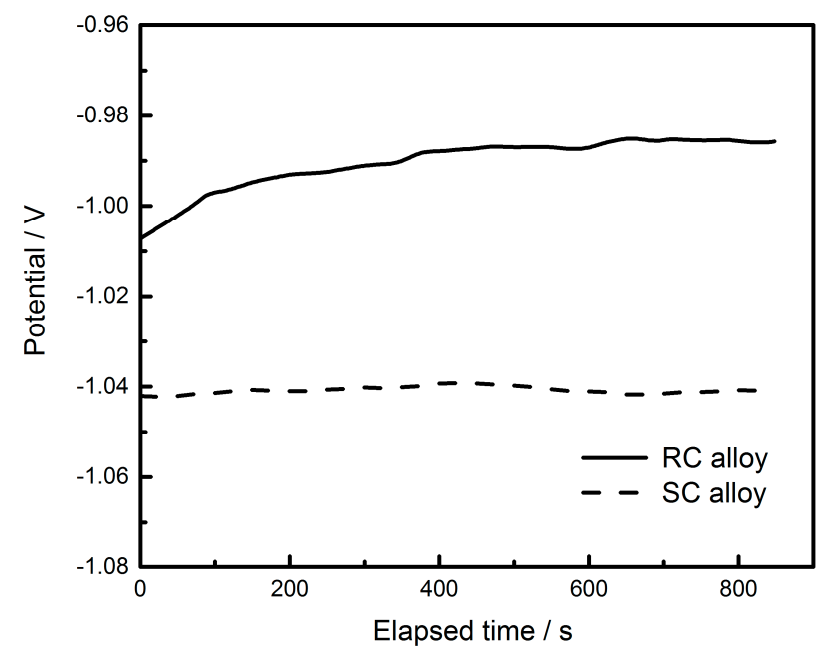

Figure 3. Open circuit potential curves for $\mathrm{Sn}-8 \mathrm{Zn}-3 \mathrm{Bi}$ solder alloy.

Moreover, polarization curves for the samples are given in Figure 4, and related values extrapolated from the polarization curves are summarized in Table 1 . The corrosion potentials $\left(\mathrm{E}_{\mathrm{corr}}\right)$ are -1.047 (SC) and $-0.999 \mathrm{~V}_{\mathrm{SCE}}(\mathrm{RC})$ for the $\mathrm{Sn}-8 \mathrm{Zn}-3 \mathrm{Bi}$ alloys, respectively. It indicates that the value of $\mathrm{E}_{\text {corr }}$ shifts towards the noble value with the increase of the cooling rate. The values of corrosion current density $\left(\mathrm{I}_{\text {corr }}\right)$ and polarization resistance $(\mathrm{Rp})$ indicate that $\mathrm{RC} \mathrm{Sn}-8 \mathrm{Zn}-3 \mathrm{Bi}$ alloy presents a lower corrosion rate and enhanced corrosion resistance compared to the SC alloy. Due to the same composition of the alloy, these results indicate that the better anticorrosive ability of the RC Sn-8Zn-3Bi alloy is strongly dependent on the transformation of the $\mathrm{Zn}$-rich phase. 


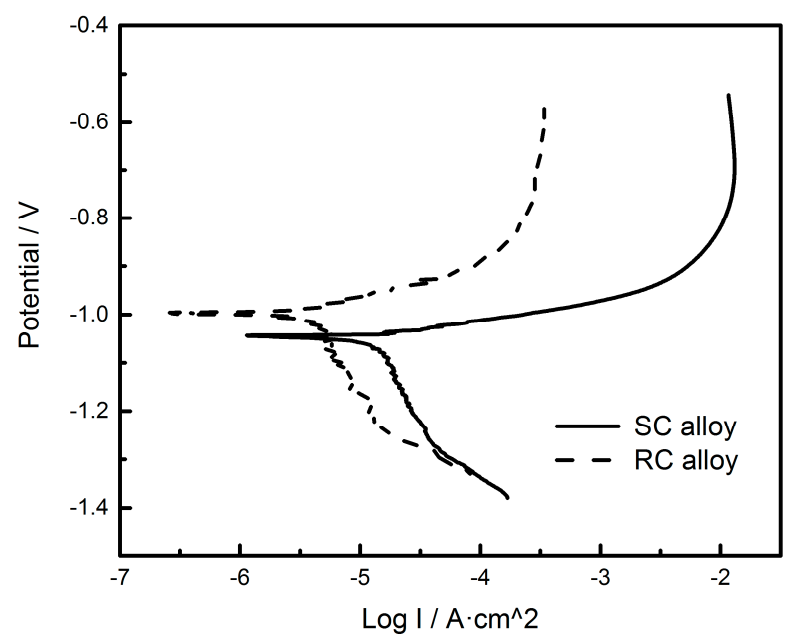

Figure 4. Potentiodynamic polarization curves of $\mathrm{Sn}-8 \mathrm{Zn}-3 \mathrm{Bi}$ solder alloy with two cooling rates in 3.5 wt. $\% \mathrm{NaCl}$ solution.

Table 1. Corrosion parameters of the studied $\mathrm{Sn}-8 \mathrm{Zn}-3 \mathrm{Bi}$ solder in $3.5 \mathrm{wt} . \% \mathrm{NaCl}$ solution at room temperature.

\begin{tabular}{ccccc}
\hline Sample & $\mathbf{E}_{\text {corr }}$ vs. SCE/ (V) & $\mathbf{I}_{\text {corr }}\left(\mathbf{A} \cdot \mathbf{c m}^{-\mathbf{2}}\right)$ & $\mathbf{R p} /\left(\Omega \cdot \mathbf{c m}^{\mathbf{2}}\right)$ & $\mathbf{O C P} /(\mathbf{V})$ \\
\hline $\mathrm{SC}$ & -1.047 & $1.298 \times 10^{-5}$ & 1490.5 & -1.042 \\
$\mathrm{RC}$ & -0.999 & $3.907 \times 10^{-6}$ & 9832.9 & -0.985 \\
\hline
\end{tabular}

To better reveal the correlation between the Zn-rich phase and the corrosion behavior of Sn-8Zn-3Bi alloy, SEM micrographs are displayed in Figure 5. The pronounced degradation of the surface morphology with immersion time can be observed. At $5 \mathrm{~h}$ of immersion in $\mathrm{NaCl}$ $3.5 \mathrm{wt} . \%$ solution, the corrosion reactions occurred along the large plate-like $\mathrm{Zn}$-rich precipitates in SC Sn-8Zn-3Bi (Figure 5a). Notably, the fine needle-like Zn-rich particles in RC alloy showed no obvious change (Figure $5 \mathrm{~b}$ ). When further increasing the duration time to $12 \mathrm{~h}$ in $3.5 \% \mathrm{NaCl}$ solution, a concomitantly low level of surface attack was observed for RC Sn-8Zn-3Bi alloy (Figure 5d). In addition, many pits and grooves could be observed, but shorter and shallower in depth compared to those in SC alloy (Figure 5c).

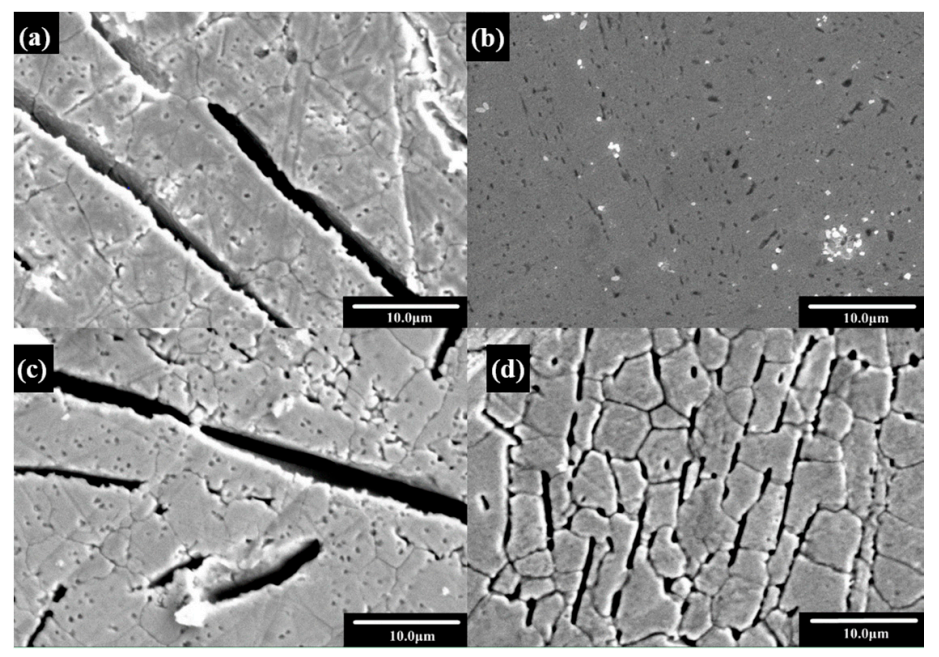

Figure 5. SEM images of Sn-8Zn-3Bi solder alloy after immersed in $3.5 \% \mathrm{NaCl}$ solution for $5 \mathrm{~h}$ ((a): SC alloy; (b): RC alloy) and $12 \mathrm{~h}$ ((c): SC alloy; (d): RC alloy). 
During the process of $\mathrm{Sn}-8 \mathrm{Zn}-3 \mathrm{Bi}$ immersed in $3.5 \% \mathrm{NaCl}$ solution, the $\mathrm{Cl}^{-}$can adsorb onto the passive film, followed by penetration through intergranular boundaries of the oxides [22]. Also, the $\mathrm{Cl}^{-}$can migrate to the film/alloy interface to react with $\mathrm{Zn}$ to form chloride complexes [23]. Continuous growth of these complexes gives rise to internal stress at the interface due to volume expansion, and thus results in the breakdown of localized regions, followed by pit initiation at the initial $\mathrm{Zn}$ sites. Moreover, because of the large solid solubility of Bi in $\mathrm{Sn}$, Bi forms a solid solution of $\mathrm{Sn}$ matrix in $\mathrm{Sn}-8 \mathrm{Zn}-3 \mathrm{Bi}$ alloy, which is expected to affect the difference of the corrosion potential between the Zn-rich phase and the Sn matrix to some extent. So, in the case of corrosion susceptibility, $\mathrm{Zn}$ still exhibits a more negative corrosion potential value than $\mathrm{Sn}$, and preferentially dissolves due to galvanic coupling and thus promotes the pitting process inwards in the alloys. This is consistent with the observation in Figure 5. Figure 6 depicts the XPS peak-fitting analysis for $Z n 2 p_{3 / 2}$ obtained from SC and RC Sn-8Zn-3Bi in $3.5 \mathrm{wt} . \% \mathrm{NaCl}$ solution, which confirms that the $\mathrm{Zn}$ element exists as $\mathrm{Zn}^{2+}$ and $\mathrm{Zn}^{\circ}$ on the surface of corroded $\mathrm{Sn}-8 \mathrm{Zn}-3 \mathrm{Bi}$ alloy. These results indicate that the amount of $\mathrm{Zn}$ has been preferentially dissolved. The formation of pits and grooves (Figure 5) is attributed to the removal of active materials, particularly $\mathrm{Zn}$.
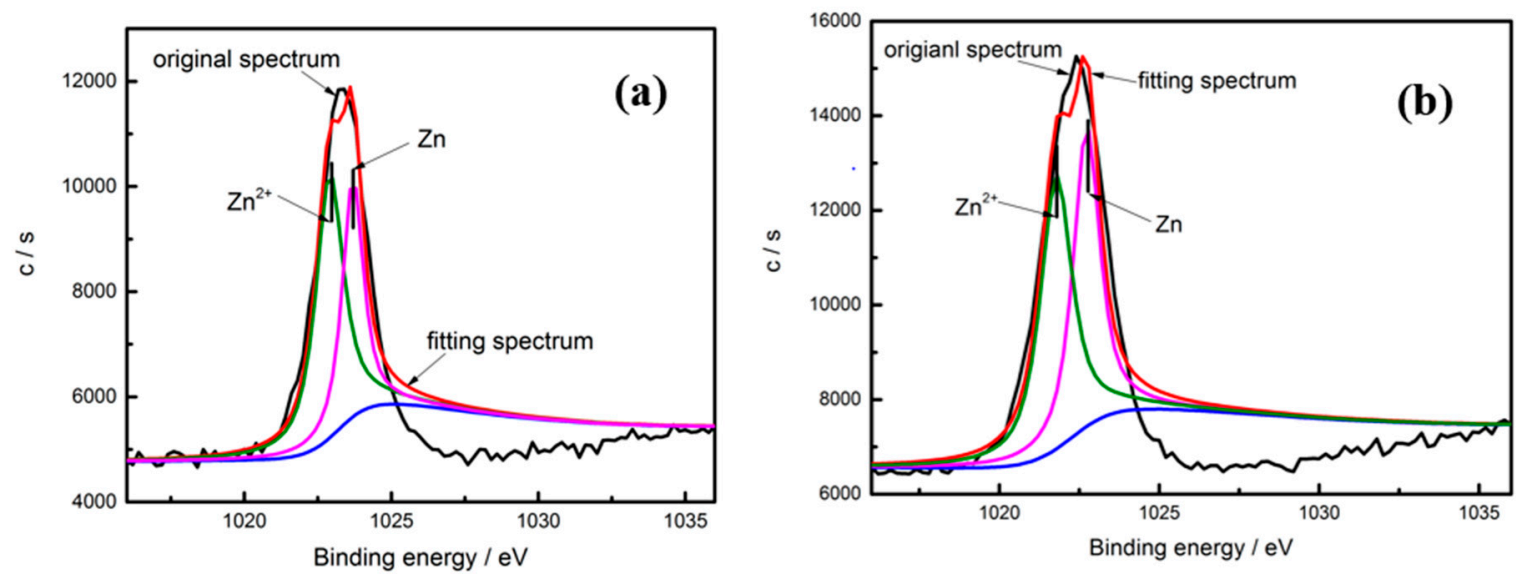

Figure 6. XPS spectrum for $\mathrm{Zn} 2 \mathrm{p}_{3 / 2}$ obtained from $\mathrm{Sn}-8 \mathrm{Zn}-3 \mathrm{Bi}$ solder alloy in $3.5 \mathrm{wt} . \% \mathrm{NaCl}$ solution at room temperature: (a) SC alloy; (b) RC alloy.

In addition, $\mathrm{Cl}^{-}$anions further migrate along the intergranular boundaries between $\mathrm{Zn}$-rich precipitates and the Sn matrix, where the boundaries can provide an efficient diffusion path to the transport of $\mathrm{Cl}^{-}$and promote the pitting process. Coarse, long, Zn-rich precipitates distribute in SC $\mathrm{Sn}-8 \mathrm{Zn}-3 \mathrm{Bi}$, corresponding to larger intergranular boundaries with lower activation energy for the dissolution of $\mathrm{Zn}$, compared to the fine, needle-like Zn-rich phase [22,24]. The corrosion oxide films around the boundaries show high activity and more defects may be formed in those regions due to the weakening of the bond between $\mathrm{Zn}$-rich precipitates and the Sn matrix, which could promote the transport of $\mathrm{Cl}^{-}$inwards in the alloy. Consequently, the pitting susceptibility of $\mathrm{Sn}-8 \mathrm{Zn}-3 \mathrm{Bi}$ increases with the increase of the size of the $\mathrm{Zn}$-rich precipitates. In other words, the $\mathrm{Sn}-8 \mathrm{Zn}-3 \mathrm{Bi}$ alloy with fine $\mathrm{Zn}$-rich precipitates shows superior protective behavior against the transport of $\mathrm{Cl}^{-}$and pitting. $\mathrm{Sn}-8 \mathrm{Zn}-3 \mathrm{Bi}$ alloys with a fine $\mathrm{Zn}$-rich phase are highly beneficial for the solder fabrication industries to achieve a superior anticorrosion behavior.

On the other hand, oxidation resistance also plays a significant role in the practical application of the lead-free solder. Figure 7 shows two samples of the time-dependence of the oxidized weight gain for $\mathrm{Sn}-8 \mathrm{Zn}-3 \mathrm{Bi}$ exposed to air atmosphere by TGA analysis. The weight gain of the alloy increases due to the oxidation of the solder. Interestingly, a more rapid increase is observed for the RC Sn-8Zn-3Bi alloy with a fine Zn-rich phase compared to the SC alloy. 


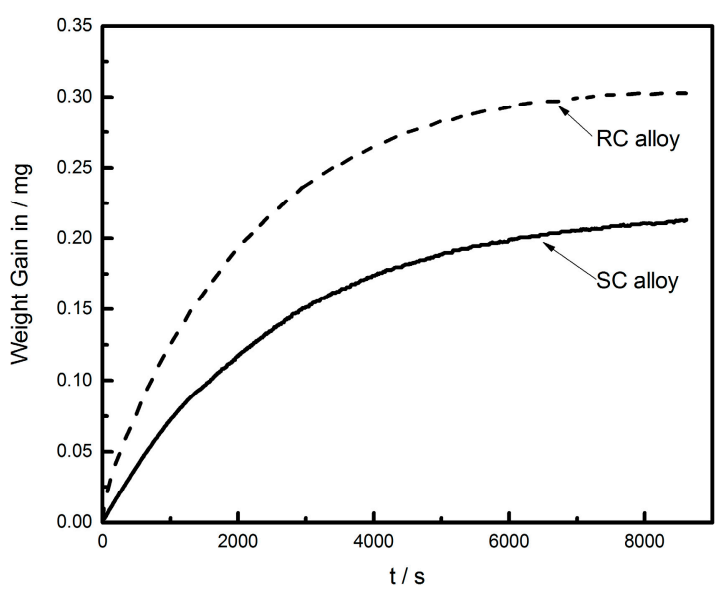

Figure 7. TGA curves of lead-free Sn-8Zn-3Bi solder alloy.

To understand the mechanism of the oxidation of the Sn-8Zn-3Bi solder, the oxidation surfaces of the samples were investigated by Auger analysis and scanning electron microscope. Figure 8 shows the results of the Auger analysis and Auger depth profiles of the two samples. In both specimens, only $\mathrm{Zn}$ and $\mathrm{O}$ elements were observed on the oxide surface without Bi and Sn. After etching a certain depth (44 nm), Bi and Sn were detected, as shown in Figure 8a,c. The result implies that the oxide $\mathrm{ZnO}$ prefers to form on the free surface of the samples.
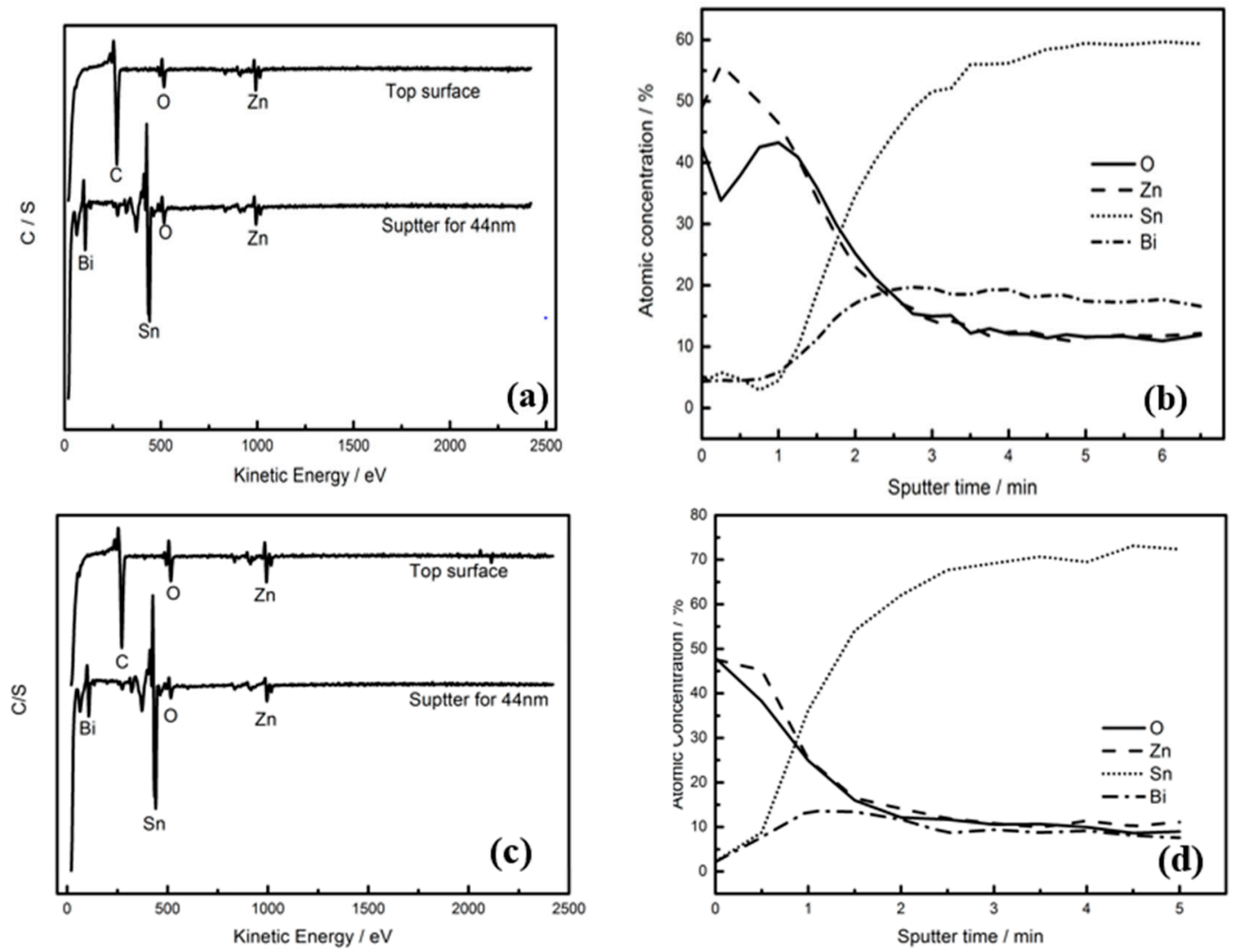

Figure 8. Auger surface analysis of RC alloy (a) and SC alloy (c); Auger depth profiles of RC alloy (b) and SC alloy (d) (from surface to etching about $20 \mathrm{~nm}$ ).

The standard Gibbs free energies of the formation of $\mathrm{ZnO}$ and $\mathrm{SnO}_{2}$ are $-300 \mathrm{~kJ} / \mathrm{mol}$ and $-237 \mathrm{~kJ} / \mathrm{mol}$, respectively [25]. As the samples were exposed to air atmosphere at $170{ }^{\circ} \mathrm{C}$, the 
$\mathrm{Zn}$ on the free surface soon reacted with oxygen and formed $\mathrm{ZnO}$ on the free surface. The phase transformation from $\mathrm{Zn}$ to $\mathrm{ZnO}$ is accompanied by a volume expansion and the stress is induced by the volume expansion of $\mathrm{ZnO}$. As a result, cracks occurred on the surface of the $\mathrm{Zn}$-rich phase, as shown in Figure 9. Moreover, $\mathrm{Zn}$ massively diffused in the Sn matrix and exhibited strong segregation from the $\mathrm{Sn}$ grain boundaries to form oxides [26,27]. Fast diffusion of $\mathrm{Zn}$ or $\mathrm{O}$ dominated the oxidation process. As a result, an oxide $\mathrm{ZnO}$ layer was formed as a uniform layer, and $\mathrm{Sn}$ and $\mathrm{Bi}$ were not segregated on the oxide surface (Figure 8a,c). As shown in Figure $8 b, d$, the oxygen concentration tends to reduce gradually with the increase of the sputtering time, indicating that the oxidation propagation takes place from the free surface to the inside of the alloy. Bi can dissolve into the Sn matrix, forming a solid solution, which causes the $\mathrm{Sn}$ matrix to become liable to form cracks and promotes the diffusion of $\mathrm{Zn} \mathrm{[27].} \mathrm{Furthermore,} \mathrm{a} \mathrm{high} \mathrm{distortion} \mathrm{energy} \mathrm{is} \mathrm{expected} \mathrm{in} \mathrm{the} \mathrm{Sn} \mathrm{lattice} \mathrm{due} \mathrm{to} \mathrm{the} \mathrm{solid} \mathrm{solution}$ formation. The high distortion energy of the Sn matrix can also promote $\mathrm{Zn}$ diffusion [28].

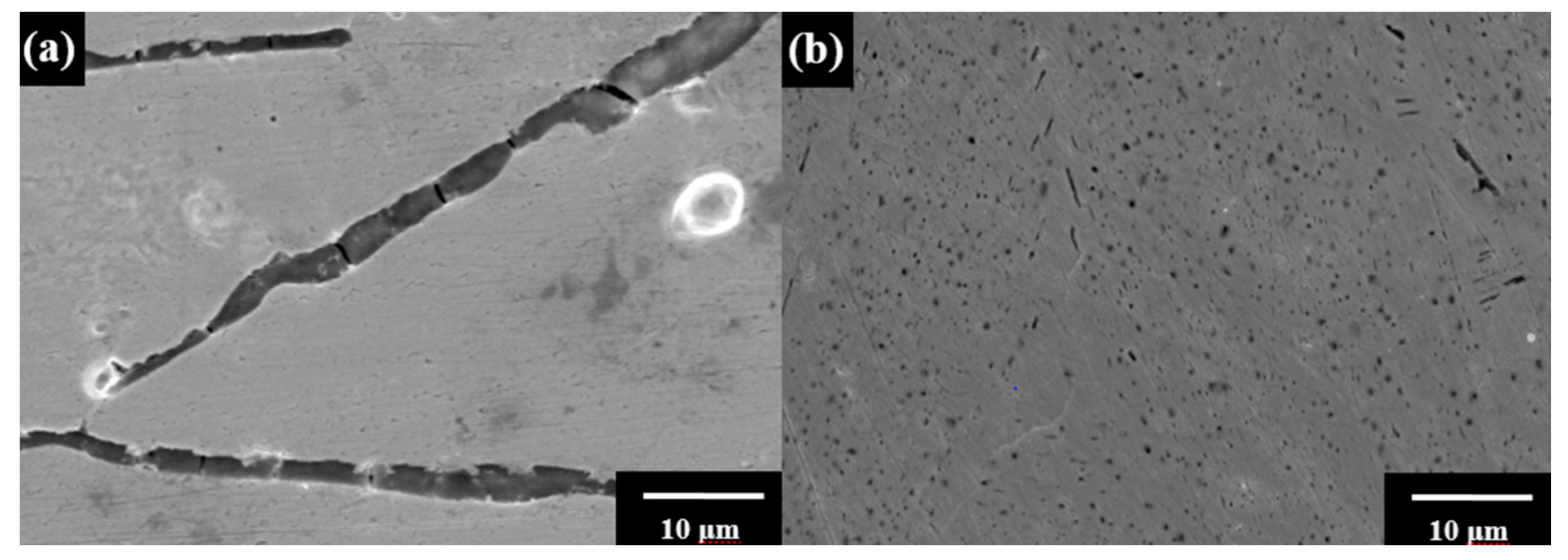

Figure 9. SEM images of Sn-8Zn-3Bi solder alloy after $170{ }^{\circ} \mathrm{C} 2 \mathrm{~h}$ exposure under air atmosphere: (a) SC alloy; (b) RC alloy.

Moreover, the oxidized layer thickness is also evaluated by the product of the sputtering time and sputtering rate. The RC Sn-8Zn-3Bi alloy has a thicker oxide layer $(16.3 \mathrm{~nm})$ than the SC alloy $(10 \mathrm{~nm})$. In the RC Sn-8Zn-3Bi alloy, the Zn-rich phase has a smaller size, higher density and more uniform distribution, in comparison to that in the SC alloy (Figure 9). Therefore, fast diffusion of $\mathrm{Zn}$ atoms in the Sn matrix with a short diffusion distance can be expected. Meanwhile, because the oxygen diffused along the interfaces between the $\mathrm{Zn}$ particles and the Sn matrix [26,27], the interdiffusion of $\mathrm{O}$ atoms is also accelerated, thus increasing the oxidation rate of the alloy. As a result, $\mathrm{Sn}-8 \mathrm{Zn}-3 \mathrm{Bi}$ alloy with a fine needle-like $\mathrm{Zn}$-rich phase shows poor oxidation resistance under air atmosphere. However, there is no reference data for diffusion coefficients obtained at the corresponding exposure condition. The detail kinetics and behavior of the $\mathrm{Sn}-8 \mathrm{Zn}-3 \mathrm{Bi}$ alloy remain a topic to be researched and determined.

\section{Conclusions}

The increase of the cooling rate significantly refines the solidification microstructure of $\mathrm{Sn}-8 \mathrm{Zn}-3 \mathrm{Bi}$ alloy. The $\mathrm{Zn}$-rich phase transforms from coarse, long flakes to fine, short needles distributed in the $\beta$-Sn matrix. In the case of corrosion susceptibility in $3.5 \% \mathrm{NaCl}$ solution, $\mathrm{Zn}$ exhibits a more negative corrosion potential value and presents preferential dissolution. The transformation of the Zn-rich precipitates results in the $\mathrm{Sn}-8 \mathrm{Zn}-3 \mathrm{Bi}$ alloy exhibiting a superior protective performance. On the contrary, as the alloy is exposed to air atmosphere at $170{ }^{\circ} \mathrm{C}$, diffusion of $\mathrm{Zn}$ or O dominates the oxidation process, and the $\mathrm{Zn}$ on the free surface reacts with oxygen and forms $\mathrm{ZnO}$ on the free surface. As a result, the refined $\mathrm{Zn}$-rich phase weakens the oxidation resistance of the $\mathrm{Sn}-8 \mathrm{Zn}-3 \mathrm{Bi}$ alloy, due to the fast diffusion of $\mathrm{Zn}$ atoms in the Sn matrix. 
Acknowledgments: This work was supported by a grant from National Science Fund for Distinguished Young Scholars of China (No. 51325401), the National Natural Science Foundation of China (No. 51404169) and the Natural Science Foundation of Tianjin (No. 15JCQNJC03200).

Author Contributions: Chong Li, Yongchang Liu and Huijun Li conceived and designed the experiments; Xin Zhang performed the experiments and wrote the manuscript; Zhiming Gao, Zongqing Ma and Liming Yu analyzed the data and revised the manuscript.

Conflicts of Interest: The authors declare no conflicts of interest.

\section{References}

1. Tu, K.N.; Zeng, K. Tin-lead (SnPb) solder reaction in flip chip technology. Mater. Sci. Eng. R 2001, 34, 1-58. [CrossRef]

2. Wood, E.P.; Nimmo, K.L. In search of new lead-free electronic solders. J. Electron. Mater. 1994, $23,709-713$. [CrossRef]

3. Guang, R.; Wilding, I.J.; Collins, M.N. Alloying influences on low melt temperature SnZn and SnBi solder alloys for electronic interconnections. J. Alloy. Compd. 2016, 665, 251-260.

4. Fawzy, A. Effect of $\mathrm{Zn}$ addition, strain rate and deformation temperature on the tensile properties of Sn-3.3 wt.\% Ag solder alloy. Mater. Charact. 2007, 58, 323-331. [CrossRef]

5. Pereira, P.D.; Spinelli, J.E.; Garcia, A. Combined effects of Ag content and cooling rate on microstructure and mechanical behavior of Sn-Ag-Cu solders. Mater. Des. 2013, 45, 377-383. [CrossRef]

6. El-Daly, A.A.; Desoky, W.M.; Saad, A.F.; Mansor, N.A.; Lotfy, E.H.; Abd-Elmoniem, H.M.; Hashem, H. The effect of undercooling on the microstructure and tensile properties of hypoeutectic $\mathrm{Sn}-6.5 \mathrm{Zn}-x \mathrm{Cu}$ Pb-free solders. Mater. Des. 2015, 80, 152-162. [CrossRef]

7. Osório, W.R.; Peixoto, L.C.; Garcia, L.R.; Noël, N.M.; Garcia, A. Microstructure and mechanical properties of $\mathrm{Sn}-\mathrm{Bi}, \mathrm{Sn}-\mathrm{Ag}$ and Sn-Zn lead-free solder. J. Alloy. Compd. 2013, 572, 97-106. [CrossRef]

8. Liu, J.C.; Zhang, G.; Wang, Z.H.; Ma, J.S.; Suganuma, K. Thermal property, wettability and interfacial characterization of novel $\mathrm{Sn}-\mathrm{Zn}$-Bi-In alloys as low-temperature lead-free solders. Mater. Des. 2015, 84, 331-339. [CrossRef]

9. Spinelli, J.E.; Silva, B.L.; Garcia, A. Assessment of tertiary dendritic growth and its effects on mechanical properties of directionally solidified Sn-0.7Cu-xAg solder alloys. J. Electron. Mater. 2014, 43, 1347-1361. [CrossRef]

10. Silva, B.L.; Cheung, N.; Garcia, A.; Spinelli, J.E. Sn-0.7 wt $\% \mathrm{Cu}-(x \mathrm{Ni})$ alloys: Microstructure-mechanical properties correlations with solder/substrate interfacial heat transfer coefficient. J. Alloy. Compd. 2015, 632, 274-285. [CrossRef]

11. Garcia, L.R.; Osório, W.R.; Peixoto, L.C.; Garcia, A. Mechanical properties of Sn-Zn lead-free solder alloys based on the microstructure array. Mater. Charact. 2010, 61, 212-220. [CrossRef]

12. Lin, S.; Xue, S.B.; Xue, P.; Luo, D.X. Present status of Sn-Zn lead-free solders bearing alloying elements. J. Mater. Sci. Mater. Electron. 2015, 26, 4389-4411.

13. El-Daly, A.A.; Hammad, A.E.; Al-Ganainy, G.S.; Ibrahiem, A.A. Design of lead-free candidate alloys for low-temperature soldering applications based on the hypoeutectic Sn-6.5Zn alloy. Mater. Des. 2014, 56, 594-603. [CrossRef]

14. Garcia, L.R.; Peixoto, L.C.; Osório, W.R.; Garcia, A. Globular to needle Zn-rich phase transition during transient solidification of a eutectic Sn-9\% Zn solder alloy. Mater. Lett. 2009, 63, 1314-1316. [CrossRef]

15. Garcia, L.R.; Osório, W.R.; Peixoto, L.C.; Garcia, A. Wetting behavior and mechanical properties of Sn-Zn and $\mathrm{Sn}-\mathrm{Pb}$ solder alloys. J. Electron. Mater. 2009, 38, 2405-2414. [CrossRef]

16. Zhou, J.; Sun, Y.S.; Xue, F. Properties of low melting point Sn-Zn-Bi solders. J. Alloy. Compd. 2005, 397, 260-264. [CrossRef]

17. Song, J.M.; Wu, Z.M. Variable eutectic temperature caused by inhomogeneous solute distribution in Sn-Zn system. Scr. Mater. 2006, 54, 1479-1483. [CrossRef]

18. Marcus, P.; Maurice, V.; Strehblow, H.H. Localized corrosion (pitting): A model of passivity breakdown including the role of the oxide layer nanostructure. Corros. Sci. 2008, 50, 2698-2704. [CrossRef]

19. Liu, N.S.; Lin, K.L. Effect of Ga on the Oxidation properties of Sn-8.5Zn-0.5Ag-0.1Al- $x$ Ga solders. Oxid. Met. 2012, 78, 285-294. [CrossRef] 
20. Kim, S.H.; Hui, K.N.; Kim, Y.J.; Lim, T.S.; Yang, D.Y.; Kim, K.B.; Kim, Y.J.; Yang, S. Oxidation resistant effects of $\mathrm{Ag}_{2} \mathrm{~S}$ in $\mathrm{Sn}-\mathrm{Ag}-\mathrm{Al}$ solder: A mechanismfor higher electrical conductivity and less whisker growth. Corros. Sci. 2016, 105, 25-35. [CrossRef]

21. Nazeri, M.F.M.; Mohamad, A.A. Corrosion resistance of ternary Sn-9Zn-xIn solder joint in alkaline solution. J. Alloy. Compd. 2016, 661, 516-525. [CrossRef]

22. Liu, J.C.; Park, S.W.; Nagao, S.; Nogi, M.; Koga, H.; Ma, J.S.; Zhang, G.; Suganuma, K. The role of Zn precipitates and $\mathrm{Cl}^{-}$anions in pitting corrosion of Sn-Zn solder alloys. Corros. Sci. 2015, 92, $263-271$. [CrossRef]

23. Burstein, G.; Liu, C.; Souto, R.; Vines, S. Origins of pitting corrosion. Corros. Eng. Sci. Technol. 2004, 39, 25-30. [CrossRef]

24. Liu, J.C.; Zhang, G.; Ma, J.S.; Suganuma, K. Ti addition to enhance corrosion resistance of Sn-Zn solder alloy by tailoring microstructure. J. Alloy. Compd. 2015, 644, 113-118. [CrossRef]

25. Barin, I. Thermochemical Data of Pure Substances; VCH: New York, NY, USA, 1995; Volume 2, p. 1549.

26. Lee, J.E.; Kim, K.S.; Inoue, M.; Jiang, J.X.; Suganuma, K. Effects of Ag and Cu addition on microstructural properties and oxidation resistance of Sn-Zn eutectic alloy. J. Alloy. Compd. 2008, 454, 310-320. [CrossRef]

27. Jiang, J.X.; Lee, J.E.; Kim, K.S.; Suganuma, K. Oxidation behavior of Sn-Zn solders under high-temperature and high-humidity conditions. J. Alloy. Compd. 2008, 462, 244-251. [CrossRef]

28. Mrowec, S. Defects and Diffusion in Solids: An Introduction; Elsevier Scientific: New York, NY, USA, 1980.

(C) 2016 by the authors; licensee MDPI, Basel, Switzerland. This article is an open access article distributed under the terms and conditions of the Creative Commons Attribution (CC-BY) license (http://creativecommons.org/licenses/by/4.0/). 